\title{
Protective and pathogenic role of humoral responses in COVID-19
}

\author{
Uni Park ${ }^{1,2}$ and Nam-Hyuk Cho ${ }^{1,2,3,4,5 *}$ \\ ${ }^{I}$ Department of Microbiology and Immunology, College of Medicine, \\ Seoul National University, Seoul 03080, Republic of Korea \\ ${ }^{2}$ Department of Biomedical Sciences, College of Medicine, Seoul National \\ University, Seoul 03080, Republic of Korea \\ ${ }^{3}$ Institute of Endemic Disease, Seoul National University Medical \\ Research Center, Seoul 03080, Republic of Korea \\ ${ }^{4}$ Seoul National University Bundang Hospital, Seongnam 13620, \\ Republic of Korea \\ ${ }^{5}$ Wide River Institute of Immunology, Seoul National University, \\ Hongcheon 25159, Republic of Korea \\ (Received Jan 28, 2022 / Revised Feb 14, 2022 / Accepted Feb 14, 2022)
}

Since the advent of SARS-CoV-2 in Dec. 2019, the global endeavor to identify the pathogenic mechanism of COVID-19 has been ongoing. Although humoral immunity including neutralizing activity play an important role in protection from the viral pathogen, dysregulated antibody responses may be associated with the pathogenic progression of COVID-19, especially in high-risk individuals. In addition, SARS-CoV-2 spike-specific antibodies acquired by prior infection or vaccination act as immune pressure, driving continuous population turnover by selecting for antibody-escaping mutations. Here, we review accumulating knowledge on the potential role of humoral immune responses in COVID-19, primarily focusing on their beneficial and pathogenic properties. Understanding the multifaceted regulatory mechanisms of humoral responses during SARS-CoV-2 infection can help us to develop more effective therapeutics, as well as protective measures against the ongoing pandemic.

Keywords: COVID-19, SARS-CoV-2, humoral immunity, antibody-escaping variants

\section{Introduction}

The coronavirus disease 2019 (COVID-19) pandemic caused by the infection of severe acute respiratory syndrome coronavirus-2 (SARS-CoV-2) has swept through the world with more than 270 million confirmed cases and about 5 million deaths (http://covid19.who.int). Many COVID-19 patients suffer from respiratory symptoms such as cough, sore throat, and shortness of breath, as well as fever, chills, headache, and diarrhea (http://korean.cdc.gov/). Although many of the confirmed cases are asymptomatic or have mild symptoms, less than $20 \%$ of patient present with severe pneumonia or acute respiratory syndrome (ARDS), and these cases are often fatal (Sharma et al., 2020; Zhao et al., 2020). Despite the global effort to elucidate the pathogenic mechanisms of COVID-19, the primary culprits of pneumonic progression leading to severe ARDS and death remain unclear.

During viral infection, adaptive immune responses, including $\mathrm{T}$ cell-mediated cellular immunity and $\mathrm{B}$ cell-mediated humoral immune responses, play an important role in protection from a major illness (Murin et al., 2019). For example, viral antigen-specific antibodies can neutralize the invading pathogens by blocking the cellular entry of SARS-CoV-2 (Dörner and Radbruch, 2007). In addition, long-lived plasma cells generated from activated $\mathrm{B}$ cells during virus infection produce antigen-specific antibodies over a long period, even in the absence of viral antigens (Slifka and Ahmed, 1998; Dörner and Radbruch, 2007; Quast and Tarlinton, 2021). These persistent antibody responses against viruses can protect the host from reinfection by the viruses (Slifka and Ahmed, 1998; Hangartner et al., 2006; Dörner and Radbruch, 2007). However, both the levels and durability of antibody responses vary depending on the patient's condition, disease severity, and the type of viral pathogens (Wiseman et al., 2020; Nguyen et al., 2021). Moreover, preformed antibodies can induce pathological side effects such as antibody-dependent enhancement (ADE). This can lead to enhanced viral infection, aberrant induction of inflammation via engagement of $\mathrm{Fc} \gamma$ receptors $(\mathrm{Fc} \gamma \mathrm{R})$ in phagocytic cells, and priming overt complement activation via the classical pathway during the reinfection of several pathogenic viruses (Morens, 1994; Xu et al., 2021). Antibodies can also pressure the emergence of antibody-escaping variants of the virus, making the current pandemic difficult to control (Lok et al., 2001; Hudu et al., 2015; Magnus et al., 2016; Gao et al., 2020; Roy, 2020; Sitaras et al., 2020).

This review summarizes and discusses current knowledge on the potential role of humoral immune responses in COVID19, primarily focusing on their beneficial and pathogenic properties (Fig. 1). Understanding the regulatory mechanisms of specific humoral responses in COVID-19 can help us develop more effective therapeutics as well as protective measures against the ongoing pandemic.

${ }^{*}$ For correspondence. E-mail: chonh@snu.ac.kr; Tel.: +82-2-740-8392; 


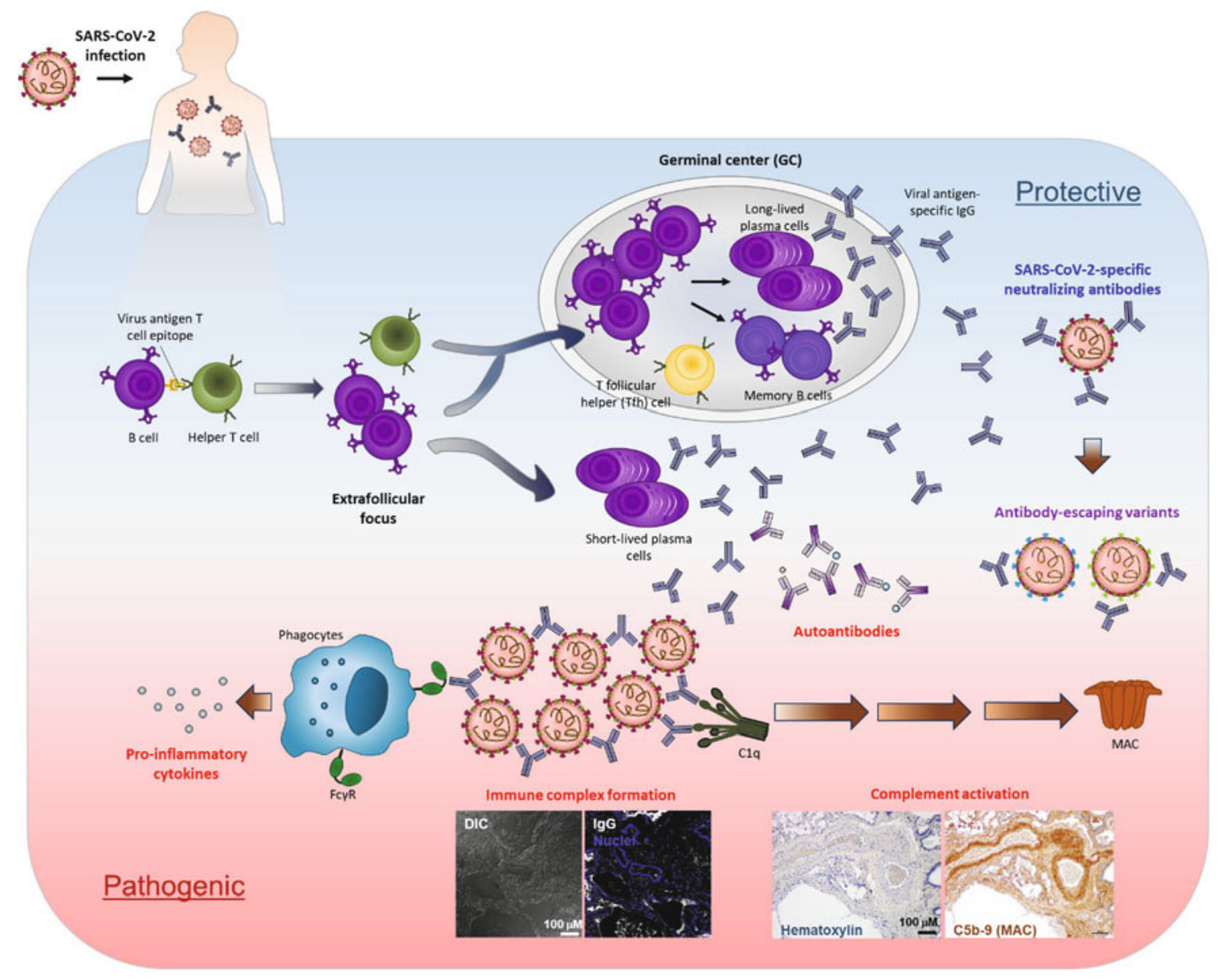

Fig. 1. Protective and pathogenic humoral responses in COVID-19 patients. During SARS-CoV-2 infection, the viral antigen is recognized by and activates both $\mathrm{B}$ cells and $\mathrm{T}$ cells. The activated $\mathrm{B}$ and $\mathrm{T}$ cells interact with each other at the interface of $\mathrm{B}$ and $\mathrm{T}$ cell zones. These interactions yield an extrafollicular focus. In the extrafollicular focus, activated B cells proliferate and differentiate into plasma cells, most of which are short-lived plasma cells. Some helper T cells can differentiate into $\mathrm{T}$ follicular helper (Tfh) cells in the extrafollicular focus, which then migrate back into the follicle with some activated B cells. This results in a germinal center (GC) formation. In the GC, activated B cells can differentiate into long-lived plasma cells or memory B cells. The viral antigenspecific antibodies secreted by plasma cells play a protective role by neutralizing viral infection. On the other hand, antibodies can also have a pathogenic effect. Autoantibody reactions against immunomodulatory proteins have been detected in some patients with severe COVID-19. SARS-CoV-2 antigenspecific antibodies can induce immune complex formation by binding viral antigens. The Fc regions of immune complex-forming antibodies interact with $\mathrm{F} c \gamma \mathrm{R}$ expressed by phagocytes; this is, followed by excessive pro-inflammatory cytokine secretion. Viral antigen-specific antibodies also can induce complement activation via the classical pathway. Immune complex and membrane-attack complex (MAC) deposition has been observed in the lungs of patients who have died of COVID-19, suggesting that dysregulated antibody responses are potential pathogenic drivers of COVID-19 progression via the induction of cytokine storms, thrombosis, and coagulopathy. SARS-CoV-2 has continued to evolve to escape host antibody responses, and the emergence of these antibody-escaping variants is among the major challenges in attempts to control this virus.

\section{Differential Antibody Responses Associated with COVID-19 Severity}

Since the advent of SARS-CoV-2, researchers have tried to identify primary factors associated with COVID-19 severity. In an acute viral infection, higher viral loads and inefficient viral clearance during the early phase of infection are generally associated with more severe outcomes. In addition, dysregulated and overt inflammation could be an additional pathogenic driver of severe disease progression. For example, during the acute phase of Dengue virus infection, the severity of the disease is primarily determined by the viral load (Morsy et al., 2020). The override of immune reactions or inflammatory responses against Influenza virus or Middle East respiratory syndrome coronavirus (MERS-CoV) can also worsen the clinical progression of these infections (Min et al., 2016; Myers et al., 2021). Although it is still contested whether SARSCoV-2 viral loads are positively correlated with disease severity, we and others have reported that the viral loads of SARS-CoV-2 in respiratory specimens may not be associated with disease severity (Fajnzylber et al., 2020; Abdulrahman et al., 2021; Kim et al., 2021c; Knudtzen et al., 2021; Trunfio et al., 2021). Nevertheless, delayed viral clearance has been observed in younger (under 60 years old) patients with severe COVID-19 and in elderly patients regardless of disease severity (Kim et al., 2021b). In addition, dysregulated immune responses or overt inflammation may be more critical risk factors associated with severe COVID-19 progression. Multiple studies on humoral responses in COVID-19 patients showed that clinical parameters or hospitalization periods were gen- 
erally correlated with higher quantities of virus-specific antibodies (Mazzoni et al., 2020; Rijkers et al., 2020; GarciaBeltran et al., 2021; Kim et al., 2021d; Lucas et al., 2021; Vigón et al., 2021). In addition, patients with the severe disease showed more rapid and robust antibody responses than patients with mild cases (Mazzoni et al., 2020; Rijkers et al., 2020; Kim et al., 2021c). This characteristic of COVID-19 contrasts with previous zoonotic coronavirus infections, including MERS and SARS, in which the specific antibody responses were significantly delayed in critical patients compared to moderate patients during the acute phase of infection (Zhang et al., 2006; Min et al., 2016; Ko et al., 2017). A recent systemic and comparative review of antibody responses in COVID-19, MERS, and SARS reported conflicting results across these coronavirus infections (Huang et al., 2020), which may have been due to inconsistent definitions of clinical grades among the studies. Nevertheless, dozens of research papers also reported a positive correlation between antibody levels and survival in COVID-19 patients.

In another study, the positivity of a specific immunoglobulin $\mathrm{G}$ (IgG) to the SARS-CoV-2 receptor binding domain (RBD) was a predictor of survival in COVID-19 patients (Secchi et al., 2020). Garcia-Beltran et al. (2021) proposed that a higher neutralization potency of antibodies predicts survival and Lucas et al. (2021) claimed that patients could recover if the neutralizing antibodies are produced within 14 days of the onset of symptoms. On the other hand, Trinité et al. (2021) found that in critical cases, patients produced more rapid and greater quantities of neutralizing antibodies than in asymptomatic or non-critical cases. More robust research with larger data sets and consistent clinical grading is required to define the specific role of antibody responses during the acute phase of primary infection in COVID-19 patients. Nevertheless, it has been generally accepted that convalescent patients who survived severe disease developed higher levels of virus-specific antibodies compared to patients with mild disease regardless of the type of zoonotic coronaviruses (Kim et al., 2021a; Wong and Perlman, 2022). More robust antibody responses and $\mathrm{B}$ cell memory could play better protective roles in the future infection of SARS-CoV-2 variants if they provide sufficient neutralizing activity (Kim et al., 2021a). In the kinetic analysis of humoral immunity in COVID-19 patients, the viral antigen-specific IgG and immunoglobulin M (IgM) seroconversion occurred within two weeks of primary infection and the level of antibodies peaked 3-5 weeks after infection (Long et al., 2020; Feng et al., 2021b). Although most patients showed seroconversion of specific IgM, followed by IgG, seroconversion for IgG and IgM can occur simultaneously (Long et al., 2020). Patients infected with other zoonotic coronaviruses maintain virus-specific antibody levels for many years after infection. SARS-CoV-specific antibodies were reported to persist up to six years post infection (Tang et al., 2011). The seropositivity in recovered MERS patients also persists for up to 4 years and decreases from the fifth year after infection (Cheon et al., 2022). The longevity of specific antibodies to MERS-CoV spike protein depends on the disease severity during the acute phase. Patients who suffered from severe pneumonia were reported to have sustained and higher levels of antibodies, neutralizing activity, and antibody-secreting B cell counts compared to patients who were asymptomatic or recovered from mild symptoms (Kim et al., 2021a; Cheon et al., 2022). In COVID-19 patients, the longevity of specific antibodies is shorter compared to that of MERS patients. The persistence of antibodies against SARSCoV-2 RBD, N, or S has been tracked in convalescent patients for more than 1 year. Studies reported that anti-S or N IgG was detected in recovered COVID-19 patients for 6 to 12 months after symptom onset, while anti-S or N IgM levels decreased rapidly from 6 months after symptom onset (Anand et al., 2021; Feng et al., 2021a; Havervall et al., 2021; Wu et al., 2021; Zhang et al., 2021). Neutralizing activity was detected as early as 6 to 17 days after symptom onset (Suthar et al., 2020; Trinité et al., 2021). The neutralizing antibodies can persist for up to 1 year in recovered COVID-19 patients (Figueiredo-Campos et al., 2020; Xiang et al., 2021), although some reports showed that neutralizing antibody levels decreased from 4 or 7 months after the initial infection (Chen et al., 2021a; Feng et al., 2021b; Legros et al., 2021). The correlation between COVID-19 severity and antibody durability has not yet been defined, due to the lack of long-term studies to demonstrate differences between groups. However, several studies have indicated that the longevity of the neutralizing antibody response correlates with COVID-19 severity (Masiá et al., 2021; Trinité et al., 2021).

In addition, accumulating somatic hypermutation was observed in temporal analysis of the antibody sequences in convalescent patients. This suggests that the maturation of antibodies occurred during the convalescent phase (Wong and Perlman, 2022). Asymptomatic or mildly symptomatic patients may not be able to generate virus-specific germinal center (GC) B cells, prohibiting them from developing vigorous and sustained antibody responses during the acute and convalescent phases (Gao et al., 2021). Long-term follow-up research is needed to confirm this relationship.

\section{Differential B Cell Immunity Associated with COVID-19 Severity}

Higher and more rapid humoral immune responses in severe COVID-19 cases can currently be explained by the following hypothesis: severe COVID-19 patients exhibit hallmarks of extrafollicular B cell activation and shared B cell repertoire features previously described in autoimmune settings (Woodruff et al., 2020). Extrafollicular activation correlates strongly with large antibody-secreting cell expansion and the early production of high concentrations of SARSCoV-2-specific neutralizing antibodies (Woodruff et al., 2020). The higher quantity and more sustained antibodies against SARS-CoV-2 antigens in severe cases may also result from the more efficient generation of viral antigen-specific B cell responses driven by Th2-skewed immunity (Kim et al., 2021c). In addition, the delayed clearance of viral antigens may support longer antigen-specific GC reactions in secondary lymphoid organs. Yang et al. (2021b) reported that asymptomatic subjects exhibited lymphopenia, a significant decrease in the B-cell population, a low frequency of antibody-secreting cells, and a low cytokine response. By contrast, patients with severe pneumonia exhibited increased B cell counts (including memory B cells and plasmablasts) despite having more severe 
lymphopenia during the acute phase of infection (MarcosJimenez et al., 2021; Vigón et al., 2021). In other studies, however, the number or frequency of total memory B cells in severe COVID-19 patients declined as a result of accumulating the "disease-relating" B cells. These include "atypical" memory (CD27') B cells and antibody secreting cells which are specific to SARS-CoV-2. This decline in B cells was followed by dysregulated humoral immune responses (De Biasi et al., 2020; Kaneko et al., 2020; Oliviero et al., 2020; Sosa-Hernandez et al., 2020). Koutsakos et al. (2021) indicated that C-X-C motif chemokine receptor 3 (CXCR3) ${ }^{+}$circulating follicular helper $\mathrm{T}\left(\mathrm{cT}_{\mathrm{FH}}\right)$ cell activation correlates to antibody levels, neutralization activity, and inflammatory cytokine (interleukin [IL]-6, soluble IL-6 receptor [sIL-6R], and IL-18) levels. However, the upregulated frequency of a cytotoxic $\mathrm{T}_{\mathrm{FH}}$ response that can eliminate B cells negatively correlates with antibody levels (Meckiff et al., 2020). Overall, these studies indicate that there is a complex dysregulation of $\mathrm{B}$ cell responses depending on the disease severity, and these could be one of the driving factors for disease progression in COVID19. Further studies are needed to analyze the specific mechanism responsible for the aberrant $\mathrm{B}$ cell differentiation.

\section{The Pathogenic Effects of Antibody Responses in COVID-19 Patients}

Virus-specific antibody responses are mainly thought to be protective. However, dysregulated antibody responses can contribute to disease progression in COVID-19 patients through worsening cytokine storms, coagulopathy, vasculopathy, and thrombosis, thereby causing pulmonary damage. Antigen-specific antibodies can form immune complexes with viral antigens and generate an exaggerated immune response through interaction with $\mathrm{F} c \gamma \mathrm{R}$-expressing immune cells (Platzer et al., 2014). Recently, we reported consistent detection of IgGpositive immune complex deposition in the vascular walls and interstitial region of the lungs in six fatal cases (Kim et al., 2021c). This indicated that the pathogenic IgG-related immune complex is associated with ARDS in fatal COVID19 cases. This observation is consistent with other studies showing immune complex deposition inside vascular walls or increased soluble immune complex in serum samples from critical COVID-19 patients (Roncati et al., 2020; Ankerhold et al., 2021; Chakraborty et al., 2021b).

Several studies have found an aberrant glycosylation, afucosylation, in the Fc glycan region of S-specific IgG in critical COVID-19 patients (Ankerhold et al., 2021; Bye et al., 2021; Chakraborty et al., 2021b). Increased afucosylated IgG in immune complexes may facilitate the interaction with Fc $\gamma$ RIIIa or Fc $\gamma$ RIIa expressed on macrophages, enhancing their activation (Nazy et al., 2020; Chakraborty et al., 2021b). The enhanced inflammatory immune complex is thought to induce cytokine storms and contribute to COVID-19 pathogenesis by causing the secretion of proinflammatory cytokines such as IL-6 and tumor necrosis factor (TNF) from phagocytic cells (Roncati et al., 2020; Chakraborty et al., 2021b; Jarlhelt et al., 2021). In addition, the immune complex with only an afucosylated IgG is reported to cause platelet-mediated thrombosis in COVID-19 patients (Nazy et al., 2020;
Bye et al., 2021). Rapid reduction of the viral release from infected host cells was observed in COVID-19 patients (Kim et al., 2021c). This facilitates binding of the rising antibodies with cells presenting viral antigens on the surface, suggesting that infected pulmonary cells of the acute COVID-19 patients could be the major targets for the antigen-antibody immune complexes (Kim et al., 2021c). On the other hand, deficient $\mathrm{B}$ cell tolerance induced by prolonged extrafollicular B cell activation may induce autoreactive antibody responses (Woodruff et al., 2020). This could potentially play a role in severe COVID-19 pathogenesis by further enhancing the formation of immune complexes. Bastard et al. (2020) demonstrated that about $10 \%$ of patients in their study cohort with critical COVID-19 pneumonia exhibited autoantibodies against type I interferons (IFNs), suggesting that preexisting autoimmunity underlies severe disease in some patients. Wang et al. (2021) identified autoantibodies against type I IFNs in $5.2 \%$ of patients who were hospitalized with COVID-19. They also found that patients with COVID-19 had high levels of autoantibodies against immunomodulatory proteins (including cytokines, chemokines, complement components, and cell-surface proteins) and that these autoantibodies perturb immune function and impair virological control by inhibiting immunoreceptor signaling and altering peripheral immune cell composition (Wang et al., 2021). Even though a variety of such autoantibodies are detected when some patients are hospitalized with severe COVID-19, there is still work to be done to determine whether these antibodies are important contributors to severe disease or an epiphenomenon of severe inflammation (Knight et al., 2021). Nevertheless, the deposition of immune complexes containing IgG bound to activated $\mathrm{F} c \gamma \mathrm{R}$ could induce the excessive inflammatory responses that cause lung damage in critically ill patients with COVID-19.

The complement activation pathway is a conserved innate humoral response against viral infection. SARS-CoV-2 infection can induce overt complement activation directly or indirectly via multiple pathways: the classical pathway, the lectin pathway, and the alternative pathway. Overt complement activation results in pathogenic progression in severe cases (Java et al., 2020; Afzali et al., 2022). In plasma from severe COVID-19 patients, we and others found higher levels of IgG1 and IgG3, as well as increased levels of activated complement components, including C3a, C3b, C4b, and C5a.; IgG1 and IgG3 are IgG subclasses primarily associated with the classical complement activation pathway (Carvelli et al., 2020; Cugno et al., 2020; Shen et al., 2020; Jarlhelt et al., 2021; Kim et al., 2021c). In addition, the concentration of the complement pathway components was correlated with the levels of the IgG subclasses, as well as the disease severity (Howell et al., 2021; Jarlhelt et al., 2021; Kim et al., 2021c). In critical COVID-19 patients, the deposition of complement components, such as membrane attack complexes (MAC), was also found in multiple tissues, including lungs, kidneys, liver, and hearts (Noris et al., 2020; Pfister et al., 2020; Kim et al., 2021c; Macor et al., 2021; Pellegrini et al., 2021). IgG immune complexes with complement components have been consistently observed in lung biopsies from fatal cases. This evidence further supports the hypothesis that immune complexes may be involved in complement-mediated pathogenesis in critical 
COVID-19 patients by promoting the classical complement pathway (Kim et al., 2021c; Macor et al., 2021). Systemic and local complement activation may induce multiple pulmonary pathologies, such as endothelialitis, hyperinflammation, and thrombotic microangiopathy (Java et al., 2020; Afzali et al., 2022). Activated complement components, including C3a, $\mathrm{C} 5 \mathrm{a}$, and MAC, play a major role in the pathogenic processes by triggering the recruitment of inflammatory neutrophils, monocytes, and macrophages (Drosos et al., 2021). The activated complement components also initiate coagulation cascades by promoting platelet and endothelial activation (Foreman et al., 1994; Kilgore et al., 1998; Skeie et al., 2010). Collectively, complement activation driven by the immune complex-mediated classical pathway can lead to lung damage and systemic cytokine storms in critical COVID-19 patients. Although antibody responses induced by the current vaccines and prior infection are considered to provide beneficial protection against future infections, the potential pathogenic role of continuously waning antibodies should be carefully monitored, especially in high-risk individuals.

\section{Antibody Responses as Immune Pressure for Selecting Antibody-Escaping Variants}

The continuous emergence and spread of new SARS-CoV-2 variants have made it difficult to control the COVID-19 pandemic. SARS-CoV-2 variants can be designated as a variant of interest (VOI) or a variant of concern (VOC) by the WHO based on its transmissibility, disease severity, or susceptibility to available vaccines and therapies (Chakraborty et al., 2021a). Currently, the delta (B.1.617.2) and omicron (B.1.1.529) variants are classified as VOCs (https://www.who.int). These variants have evolved to increase their binding affinity to the host receptor to enhance infectivity and/or transmissibility. In addition, they are capable of escaping pre-formed host antibodies induced by previous infections and vaccines. The SARS-CoV-2 variants contain amino acid substitutions in regions of the spike protein, which is involved in virus entry by binding to the host receptor ACE2. Although the roles of each substitution in the variants are not clearly defined, most conserved mutations in the spike protein may be associated with increased transmissibility and/or binding affinity to the ACE2 receptor, as well as decreased susceptibility to preexisting neutralizing antibodies (Weisblum et al., 2020; Yang et al., 2021a). The B.1.617 variants, including the kappa and delta variants, had higher infectivity and greater resistance to neutralizing antibodies compared to the ancestral SARS-CoV2 D614G mutant (Hu et al., 2021). The omicron variant is rapidly spreading worldwide and also shows lower neutralizing sensitivity against immune sera from convalescent patients or vaccinated individuals (Ai et al., 2022; Wang et al., 2022). In particular, the K417N/T, E484K/Q, and N501Y substitutions, which are common in the spike protein of SARSCoV-2 variants such as alpha (B.1.1.7), beta (B.1.351), gamma (P.1), delta, and omicron variants that were once or are currently designated as VOCs, are likely to be highly resistant to neutralizing antibodies (Chen et al., 2021b; Garcia-Beltran et al., 2021; Lubin et al., 2021; Liu et al., 2022). The L452R substitution in the omicron variant spike protein may reduce the antibody binding affinity, which indicated an antibody escaping mutation (Yang et al., 2021a). Therefore, SARS-CoV2 -specific antibodies acquired by prior infection or vaccination continuously confer selective pressure on SARS-CoV2 , resulting in ongoing antibody-escaping mutations. Establishing stable host adaptation is a common strategy of coronavirus evolution. Moreover, as observed in other human coronaviruses, it's now clear that the decreased neutralization of "future" SARS-CoV-2 will be ongoing due to the antigenic evolution of the viral spike, especially in the RBD (Eguia et al., 2021). Therefore, SARS-CoV-2 vaccines may need to be periodically updated before there is a universal vaccine platform (Morens et al., 2022).

\section{Conclusion}

This review summarized and discussed the beneficial and pathogenic characteristics of antibody responses in COVID19 patients based on rapidly accumulating evidence since the start of the COVID-19 pandemic. There have been conflicting data on several critical issues, and there are still unresolved questions regarding the critical drivers of severe COVID-19. However, it is becoming clear that dysregulation of specific immunity, including humoral responses, and overt inflammatory reactions, may be one of the primary culprits that could serve as a specific target for better therapeutic interventions. In addition, antibody-escaping SARSCoV-2 variants are continuously emerging, driven by the selective pressure of pre-existing antibodies. This calls for carefully monitoring the potential adverse effect of continuously waning antibodies, particularly in high-risk individuals. Furthermore, the limitations of the current SARS-CoV-2 vaccines suggest that they will need to be replaced by more efficient vaccines that induce more broadly protective and durable immunity.

\section{Acknowledgements}

This work was supported by a grant from the National Research Foundation of Korea (grant no. 2021M3A9H5020761).

\section{Conflict of Interest}

The authors have no conflict of interest to report.

\section{References}

Abdulrahman, A., Mallah, S.I., and Alqahtani, M. 2021. COVID19 viral load not associated with disease severity: findings from a retrospective cohort study. BMC Infect. Dis. 21, 688.

Afzali, B., Noris, M., Lambrecht, B.N., and Kemper, C. 2022. The state of complement in COVID-19. Nat. Rev. Immunol. 22, 77-84.

Ai, J., Zhang, H., Zhang, Y., Lin, K., Zhang, Y., Wu, J., Wan, Y., Huang, Y., Song, J., Fu, Z., et al. 2022. Omicron variant showed lower neutralizing sensitivity than other SARS-CoV-2 variants to immune sera elicited by vaccines after boost. Emerg. Microbes Infect. 11, 337-343. 
Anand, S.P., Prévost, J., Nayrac, M., Beaudoin-Bussières, G., Benlarbi, M., Gasser, R., Brassard, N., Laumaea, A., Gong, S.Y., Bourassa, C., et al. 2021. Longitudinal analysis of humoral immunity against SARS-CoV-2 Spike in convalescent individuals up to 8 months post-symptom onset. Cell Rep. Med. 2, 100290.

Ankerhold, J., Giese, S., Kolb, P., Maul-Pavicic, A., Göppert, N., Ciminski, K., Kreutz, C., Lother, A., Salzer, U., Bildl, W., et al. 2021. Circulating immune complexes drive immunopathology in COVID19. bioRxiv. doi: https://doi.org/10.1101/2021.06.25.449893.

Bastard, P., Rosen, L.B., Zhang, Q., Michailidis, E., Hoffmann, H.H., Zhang, Y., Dorgham, K., Philippot, Q., Rosain, J., Béziat, V., et al. 2020. Autoantibodies against type I IFNs in patients with lifethreatening COVID-19. Science 370, eabd 4585.

Bye, A.P., Hoepel, W., Mitchell, J.L., Jégouic, S., Loureiro, S., Sage, T., Vidarsson, G., Nouta, J., Wuhrer, M., de Taeye, S., et al. 2021 Aberrant glycosylation of anti-SARS-CoV-2 spike IgG is a prothrombotic stimulus for platelets. Blood 138, 1481-1489.

Carvelli, J., Demaria, O., Vély, F., Batista, L., Chouaki Benmansour, N., Fares, J., Carpentier, S., Thibult, M.L., Morel, A., Remark, R., et al. 2020. Association of COVID-19 inflammation with activation of the C5a-C5aR1 axis. Nature 588, 146-150.

Chakraborty, C., Bhattacharya, M., and Sharma, A.R. 2021a. Present variants of concern and variants of interest of severe acute respiratory syndrome coronavirus 2: Their significant mutations in S-glycoprotein, infectivity, re-infectivity, immune escape and vaccines activity. Rev. Med. Virol. e2270.

Chakraborty, S., Gonzalez, J., Edwards, K., Mallajosyula, V., Buzzanco, A.S., Sherwood, R., Buffone, C., Kathale, N., Providenza, S., Xie, M.M., et al. 2021b. Proinflammatory IgG Fc structures in patients with severe COVID-19. Nat. Immunol. 22, 67-73.

Chen, J., Liu, X., Zhang, X., Lin, Y., Liu, D., Xun, J., Wang, Z., Gu, L., Li, Q., Yin, D., et al. 2021a. Decline in neutralising antibody responses, but sustained T-cell immunity, in COVID-19 patients at 7 months post-infection. Clin. Transl. Immunol. 10, e1319.

Chen, L.L., Lu, L., Choi, C.Y.K., Cai, J.P., Tsoi, H.W., Chu, A.W.H., Ip, J.D., Chan, W.M., Zhang, R.R., Zhang, X., et al. 2021b. Impact of SARS-CoV-2 variant-associated RBD mutations on the susceptibility to serum antibodies elicited by COVID-19 infection or vaccination. Clin. Infect. Dis. ciab656.

Cheon, S., Park, U., Park, H., Kim, Y., Nguyen, Y.T.H., Aigerim, A., Rhee, J.Y., Choi, J.P., Park, W.B., Park, S.W., et al. 2022. Longevity of seropositivity and neutralizing antibodies in recovered MERS patients: a 5-year follow-up study. Clin. Microbiol. Infect. 28, 292-296.

Cugno, M., Meroni, P.L., Gualtierotti, R., Griffini, S., Grovetti, E., Torri, A., Panigada, M., Aliberti, S., Blasi, F., Tedesco, F., et al. 2020. Complement activation in patients with COVID-19: A novel therapeutic target. J. Allergy Clin. Immunol. 146, 215-217.

De Biasi, S., Lo Tartaro, D., Meschiari, M., Gibellini, L., Bellinazzi, C., Borella, R., Fidanza, L., Mattioli, M., Paolini, A., Gozzi, L., et al. 2020. Expansion of plasmablasts and loss of memory B cells in peripheral blood from COVID-19 patients with pneumonia. Eur. J. Immunol. 50, 1283-1294.

Dörner, T. and Radbruch, A. 2007. Antibodies and B cell memory in viral immunity. Immunity 27, 384-392.

Drosos, A.A., Pelechas, E., and Voulgari, P.V. 2021. Seronegative erosive arthritis following SARS-CoV-2 infection. Rheumatol. Ther. 9, 295-301.

Eguia, R.T., Crawford, K.H.D., Stevens-Ayers, T., Kelnhofer-Millevolte, L., Greninger, A.L., Englund, J.A., Boeckh, M.J., and Bloom, J.D. 2021. A human coronavirus evolves antigenically to escape antibody immunity. PLoS Pathog. 17, e1009453.

Fajnzylber, J., Regan, J., Coxen, K., Corry, H., Wong, C., Rosenthal, A., Worrall, D., Giguel, F., Piechocka-Trocha, A., Atyeo, C., et al. 2020. SARS-CoV-2 viral load is associated with increased disease severity and mortality. Nat. Commun. 11, 5493.

Feng, C., Shi, J., Fan, Q., Wang, Y., Huang, H., Chen, F., Tang, G., Li,
Y., Li, P., Li, J., et al. 2021a. Protective humoral and cellular immune responses to SARS-CoV-2 persist up to 1 year after recovery. Nat. Commun. 12, 4984.

Feng, X., Yin, J., Zhang, J., Hu, Y., Ouyang, Y., Qiao, S., Zhao, H., Zhang, T., Li, X., Zhang, L., et al. 2021b. Longitudinal profiling of antibody response in patients with COVID-19 in a tertiary care hospital in Beijing, China. Front. Immunol. 12, 614436.

Figueiredo-Campos, P., Blankenhaus, B., Mota, C., Gomes, A., Serrano, M., Ariotti, S., Costa, C., Nunes-Cabaco, H., Mendes, A.M., Gaspar, P., et al. 2020. Seroprevalence of anti-SARS-CoV-2 antibodies in COVID-19 patients and healthy volunteers up to 6 months post disease onset. Eur. J. Immunol. 50, 2025-2040.

Foreman, K.E., Vaporciyan, A.A., Bonish, B.K., Jones, M.L., Johnson, K.J., Glovsky, M.M., Eddy, S.M., and Ward, P.A. 1994. C5a-induced expression of P-selectin in endothelial-cells. J. Clin. Invest. 94, 1147-1155.

Gao, R., Sreenivasan, C.C., Sheng, Z., Hause, B.M., Zhou, B., Wentworth, D.E., Clement, T., Rausch, D., Brunick, C., ChristopherHennings, J., et al. 2020. Human monoclonal antibody derived from transchromosomic cattle neutralizes multiple $\mathrm{H} 1$ clades of influenza A virus by recognizing a novel conformational epitope in the hemagglutinin head domain. J. Virol. 94, e00945-20.

Gao, L., Zhou, J., Yang, S., Wang, L., Chen, X., Yang, Y., Li, R., Pan, Z., Zhao, J., Li, Z., et al. 2021. The dichotomous and incomplete adaptive immunity in COVID-19 patients with different disease severity. Sig. Transduct. Target. Ther. 6, 113.

Garcia-Beltran, W.F., Lam, E.C., Astudillo, M.G., Yang, D., Miller, T.E., Feldman, J., Hauser, B.M., Caradonna, T.M., Clayton, K.L., Nitido, A.D., et al. 2021. COVID-19-neutralizing antibodies predict disease severity and survival. Cell 184, 476-488.

Hangartner, L., Zinkernagel, R.M., and Hengartner, H. 2006. Antiviral antibody responses: the two extremes of a wide spectrum. Nat. Rev. Immunol. 6, 231-243.

Havervall, S., Ng, H., Falk, A.J., Greilert-Norin, N., Månberg, A., Marking, U., Laurén, I., Gabrielsson, L., Salomonsson, A.C., Aguilera, K., et al. 2021. Robust humoral and cellular immune responses and low risk for reinfection at least 8 months following asymptomatic to mild COVID-19. J. Intern. Med. 291, 72-80.

Howell, M.C., Green, R., McGill, A.R., Kahlil, R.M., Dutta, R., Mohapatra, S.S., and Mohapatra, S. 2021. Activation of intracellular complement in lungs of patients with severe COVID-19 disease decreases T-cell activity in the lungs. Front. Immunol. 12, 700705.

Hu, J., Wei, X.Y., Xiang, J., Peng, P., Xu, F.L., Wu, K., Luo, F.Y., Jin, A.S., Fang, L., Liu, B.Z., et al. 2021. Reduced neutralization of SARS-CoV-2 B.1.617 variant by convalescent and vaccinated sera. Genes Dis. doi: 10.1016/j.gendis.2021.11.007.

Huang, A.T., Garcia-Carreras, B., Hitchings, M.D.T., Yang, B., Katzelnick, L.C., Rattigan, S.M., Borgert, B.A., Moreno, C.A., Solomon, B.D., Trimmer-Smith, L., et al. 2020. A systematic review of antibody mediated immunity to coronaviruses: kinetics, correlates of protection, and association with severity. Nat. Commun. 11, 4704.

Hudu, S.A., Harmal, N.S., Saeed, M.I., Alshrari, A.S., Malik, Y.A., Niazlin, M.T., Hassan, R., and Sekawi, Z. 2015. Naturally occurring hepatitis $B$ virus surface antigen mutant variants in Malaysian blood donors and vaccinees. Eur. J. Clin. Microbiol. Infect. Dis. 34, 1349-1359.

Jarlhelt, I., Nielsen, S.K., Jahn, C.X.H., Hansen, C.B., Pérez-Alós, L., Rosbjerg, A., Bayarri-Olmos, R., Skjoedt, M.O., and Garred, P. 2021. SARS-CoV-2 antibodies mediate complement and cellular driven inflammation. Front. Immunol. 12, 767981.

Java, A., Apicelli, A.J., Liszewski, M.K., Coler-Reilly, A., Atkinson, J.P., Kim, A.H., and Kulkarni, H.S. 2020. The complement system in COVID-19: friend and foe? JCI Insight 5, e140711.

Kaneko, N., Kuo, H.H., Boucau, J., Farmer, J.R., Allard-Chamard, H., Mahajan, V.S., Piechocka-Trocha, A., Lefteri, K., Osborn, M., Bals, J., et al. 2020. Loss of Bcl-6-expressing T follicular helper 
cells and germinal centers in COVID-19. Cell 183, 143-157.

Kilgore, K.S., Ward, P.A., and Warren, J.S. 1998. Neutrophil adhesion to human endothelial cells is induced by the membrane attack complex: the roles of P-selectin and platelet activating factor. Inflammation 22, 583-598.

Kim, Y.S., Aigerim, A., Park, U., Kim, Y., Park, H., Rhee, J.Y., Choi, J.P., Park, W.B., Park, S.W., Kim, Y., et al. 2021a. Sustained responses of neutralizing antibodies against Middle East respiratory syndrome coronavirus (MERS-CoV) in recovered patients and their therapeutic applicability. Clin. Infect. Dis. 73, e550e558.

Kim, Y., Cheon, S., Jeong, H., Park, U., Ha, N.Y., Lee, J., Sohn, K.M., Kim, Y.S., and Cho, N.H. 2021b. Differential association of viral dynamics with disease severity depending on patients' age group in COVID-19. Front. Microbiol. 12, 712260.

Kim, D.M., Kim, Y., Seo, J.W., Lee, J., Park, U., Ha, N.Y., Koh, J., Park, H., Lee, J.W., Ro, H.J., et al. 2021c. Enhanced eosinophilmediated inflammation associated with antibody and complement-dependent pneumonic insults in critical COVID-19. Cell Rep. 37, 109798.

Kim, J.Y., Kwon, J.S., Bae, S., Cha, H.H., Lim, J.S., Kim, M.C., Chung, J.W., Park, S.Y., Lee, M.J., Kim, B.N., et al. 2021d. SARS CoV-2-specific antibody and $\mathrm{T}$ cell response kinetics according to symptom severity. Am. J. Trop. Med. Hyg. 105, 395-400.

Knight, J.S., Caricchio, R., Casanova, J.L., Combes, A.J., Diamond, B., Fox, S.E., Hanauer, D.A., James, J.A., Kanthi, Y., Ladd, V., et al. 2021. The intersection of COVID-19 and autoimmunity. J. Clin. Invest. 131, e154886.

Knudtzen, F.C., Jensen, T.G., Lindvig, S.O., Rasmussen, L.D., Madsen, L.W., Hoegh, S.V., Bek-Thomsen, M., Laursen, C.B., Nielsen, S.L., and Johansen, I.S. 2021. SARS-CoV-2 viral load as a predictor for disease severity in outpatients and hospitalised patients with COVID-19: a prospective cohort study. PLOS ONE 16, e0258421.

Ko, J.H., Müller, M.A., Seok, H., Park, G.E., Lee, J.Y., Cho, S.Y., Ha, Y.E., Baek, J.Y., Kim, S.H., Kang, J.M., et al. 2017. Serologic responses of 42 MERS-coronavirus-infected patients according to the disease severity. Diagn. Microbiol. Infect. Dis. 89, 106-111.

Koutsakos, M., Rowntree, L.C., Hensen, L., Chua, B.Y., van de Sandt, C.E., Habel, J.R., Zhang, W., Jia, X., Kedzierski, L., Ashhurst, T.M., et al. 2021. Integrated immune dynamics define correlates of COVID-19 severity and antibody responses. Cell Rep. Med. 2 , 100208.

Legros, V., Denolly, S., Vogrig, M., Boson, B., Siret, E., Rigaill, J., Pillet, S., Grattard, F., Gonzalo, S., Verhoeven, P., et al. 2021. A longitudinal study of SARS-CoV-2-infected patients reveals a high correlation between neutralizing antibodies and COVID-19 severity. Cell. Mol. Immunol. 18, 318-327.

Liu, C., Zhou, D., Nutalai, R., Duyvesteyn, H.M.E., Tuekprakhon, A., Ginn, H.M., Dejnirattisai, W., Supasa, P., Mentzer, A.J., Wang, B., et al. 2022. The antibody response to SARS-CoV-2 beta underscores the antigenic distance to other variants. Cell Host Microbe 30, 53-63.

Lok, S.M., Ng, M.L., and Aaskov, J. 2001. Amino acid and phenotypic changes in dengue 2 virus associated with escape from neutralisation by IgM antibody. J. Med. Virol. 65, 315-323.

Long, Q.X., Liu, B.Z., Deng, H.J., Wu, G.C., Deng, K., Chen, Y.K., Liao, P., Qiu, J.F., Lin, Y., Cai, X.F., et al. 2020. Antibody responses to SARS-CoV-2 in patients with COVID-19. Nat. Med. 26, 845848.

Lubin, J.H., Markosian, C., Balamurugan, D., Pasqualini, R., Arap, W., Burley, S.K., and Khare, S.D. 2021. Structural models of SARSCoV-2 Omicron variant in complex with ACE2 receptor or antibodies suggest altered binding interfaces. bioRxiv. doi: https:// doi.org/10.1101/2021.12.12.472313.

Lucas, C., Klein, J., Sundaram, M.E., Liu, F., Wong, P., Silva, J., Mao, T., Oh, J.E., Mohanty, S., Huang, J., et al. 2021. Delayed production of neutralizing antibodies correlates with fatal COVID-19.
Nat. Med. 27, 1178-1186.

Macor, P., Durigutto, P., Mangogna, A., Bussani, R., De Maso, L., D'Errico, S., Zanon, M., Pozzi, N., Meroni, P.L., and Tedesco, F. 2021. Multiple-organ complement deposition on vascular endothelium in COVID-19 Patients. Biomedicines 9, 1003.

Magnus, C., Reh, L., and Trkola, A. 2016. HIV-1 resistance to neutralizing antibodies: determination of antibody concentrations leading to escape mutant evolution. Virus Res. 218, 57-70.

Marcos-Jiménez, A., Sánchez-Alonso, S., Alcaraz-Serna, A., Esparcia, L., López-Sanz, C., Sampedro-Núñez, M., Mateu-Albero, T., Sánchez-Cerrillo, I., Martínez-Fleta, P., Gabrie, L., et al. 2021. Deregulated cellular circuits driving immunoglobulins and complement consumption associate with the severity of COVID-19 patients. Eur. J. Immunol. 51, 634-647.

Masiá, M., Fernández-González, M., Telenti, G., Agulló, V., García, J.A., Padilla, S., Garcia-Abellan, J., Galiana, A., Gonzalo-Jiménez, N., and Gutiérrez, F. 2021. Durable antibody response one year after hospitalization for COVID-19: a longitudinal cohort study. J. Autoimmun. 123, 102703.

Mazzoni, A., Maggi, L., Capone, M., Spinicci, M., Salvati, L., Colao, M.G., Vanni, A., Kiros, S.T., Mencarini, J., Zammarchi, L., et al. 2020. Cell-mediated and humoral adaptive immune responses to SARS-CoV-2 are lower in asymptomatic than symptomatic COVID-19 patients. Eur. J. Immunol. 50, 2013-2024.

Meckiff, B.J., Ramírez-Suástegui, C., Fajardo, V., Chee, S.J., Kusnadi, A., Simon, H., Eschweiler, S., Grifoni, A., Pelosi, E., Weiskopf, D., et al. 2020. Imbalance of regulatory and cytotoxic SARS-CoV-2reactive $\mathrm{CD}^{+}{ }^{+} \mathrm{T}$ cells in COVID-19. Cell 183, 1340-1353.

Min, C.K., Cheon, S., Ha, N.Y., Sohn, K.M., Kim, Y., Aigerim, A., Shin, H.M., Choi, J.Y., Inn, K.S., Kim, J.H., et al. 2016. Comparative and kinetic analysis of viral shedding and immunological responses in MERS patients representing a broad spectrum of disease severity. Sci. Rep. 6, 25359.

Morens, D.M. 1994. Antibody-dependent enhancement of infection and the pathogenesis of viral disease. Clin. Infect. Dis. 19, 500-512.

Morens, D.M., Taubenberger, J.K., and Fauci, A.S. 2022. Universal coronavirus vaccines - an urgent need. N. Engl. J. Med. 386, 297299.

Morsy, S., Hashan, M.R., Hieu, T.H., Mohammed, A.T., Elawady, S.S., Ghosh, P., Elgendy, M.A., Le, H.H., Hamad, W.M.A., Iqtadar, S., et al. 2020. The association between dengue viremia kinetics and dengue severity: a systemic review and meta-analysis. Rev. Med. Virol. 30, 1-10.

Murin, C.D., Wilson, I.A., and Ward, A.B. 2019. Antibody responses to viral infections: a structural perspective across three different enveloped viruses. Nat. Microbiol. 4, 734-747.

Myers, M.A., Smith, A.P., Lane, L.C., Moquin, D.J., Aogo, R., Woolard, S., Thomas, P., Vogel, P., and Smith, A.M. 2021. Dynamically linking influenza virus infection kinetics, lung injury, inflammation, and disease severity. eLife 10, e68864.

Nazy, I., Jevtic, S.D., Moore, J.C., Huynh, A., Smith, J.W., Kelton, J.G., and Arnold, D.M. 2020. Platelet activating immune complexes identified in COVID-19 associated coagulopathy. medRxiv. doi: https://doi.org/10.1101/2020.11.04.20226076.

Nguyen, H.D., Chaudhury, S., Waickman, A.T., Friberg, H., Currier, J.R., and Wallqvist, A. 2021. Stochastic model of the adaptive immune response predicts disease severity and captures enhanced cross-reactivity in natural dengue infections. Front. Immunol. 12, 696755.

Noris, M., Benigni, A., and Remuzzi, G. 2020. The case of complement activation in COVID-19 multiorgan impact. Kidney Int. 98, 314-322.

Oliviero, B., Varchetta, S., Mele, D., Mantovani, S., Cerino, A., Perotti, C.G., Ludovisi, S., and Mondelli, M.U. 2020. Expansion of atypical memory B cells is a prominent feature of COVID-19. Cell. Mol. Immunol. 17, 1101-1103.

Pellegrini, D., Kawakami, R., Guagliumi, G., Sakamoto, A., Kawai, 
K., Gianatti, A., Nasr, A., Kutys, R., Guo, L., Cornelissen, A., et al. 2021. Microthrombi as a major cause of cardiac injury in COVID19: a pathologic study. Circulation 143, 1031-1042.

Pfister, F., Vonbrunn, E., Ries, T., Jäck, H.M., Überla, K., Lochnit, G., Sheriff, A., Herrmann, M., Büttner-Herold, M., Amann, K., et al. 2020. Complement activation in kidneys of patients with COVID-19. Front. Immunol. 11, 594849.

Platzer, B., Stout, M., and Fiebiger, E. 2014. Antigen cross-presentation of immune complexes. Front. Immunol. 5, 140.

Quast, I. and Tarlinton, D. 2021. B cell memory: understanding COVID-19. Immunity 54, 205-210.

Rijkers, G., Murk, J.L., Wintermans, B., van Looy, B., van den Berge, M., Veenemans, J., Stohr, J., Reusken, C., van der Pol, P., and Reimerink, J. 2020. Differences in antibody kinetics and functionality between severe and mild severe acute respiratory syndrome coronavirus 2 infections. J. Infect. Dis. 222, 1265-1269.

Roncati, L., Ligabue, G., Fabbiani, L., Malagoli, C., Gallo, G., Lusenti, B., Nasillo, V., Manenti, A., and Maiorana, A. 2020. Type 3 hypersensitivity in COVID-19 vasculitis. Clin. Immunol. 217, 108487.

Roy, U. 2020. Structural and molecular analyses of functional epitopes and escape mutants in Japanese encephalitis virus envelope protein domain III. Immunol. Res. 68, 81-89.

Secchi, M., Bazzigaluppi, E., Brigatti, C., Marzinotto, I., Tresoldi, C., Rovere-Querini, P., Poli, A., Castagna, A., Scarlatti, G., Zangrillo, A., et al. 2020. COVID-19 survival associates with the immunoglobulin response to the SARS-CoV-2 spike receptor binding domain. J. Clin. Invest. 130, 6366-6378.

Sharma, A., Tiwari, S., Deb, M.K., and Marty, J.L. 2020. Severe acute respiratory syndrome coronavirus-2 (SARS-CoV-2): a global pandemic and treatment strategies. Int. J. Antimicrob. Agents 56, 106054

Shen, B., Yi, X., Sun, Y., Bi, X., Du, J., Zhang, C., Quan, S., Zhang, F., Sun, R., Qian, L., et al. 2020. Proteomic and metabolomic characterization of COVID-19 patient sera. Cell 182, 59-72.

Sitaras, I., Spackman, E., de Jong, M.C.M., and Parris, D.J. 2020. Selection and antigenic characterization of immune-escape mutants of H7N2 low pathogenic avian influenza virus using homologous polyclonal sera. Virus Res. 290, 198188.

Skeie, J.M., Fingert, J.H., Russell, S.R., Stone, E.M., and Mullins, R.F. 2010. Complement component C5a activates ICAM-1 expression on human choroidal endothelial cells. Invest. Ophthalmol. Vis. Sci. 51, 5336-5342.

Slifka, M.K. and Ahmed, R. 1998. Long-lived plasma cells: a mechanism for maintaining persistent antibody production. Curr. Opin. Immunol. 10, 252-258.

Sosa-Hernández, V.A., Torres-Ruíz, J., Cervantes-Díaz, R., RomeroRamírez, S., Páez-Franco, J.C., Meza-Sánchez, D.E., Juárez-Vega, G., Pérez-Fragoso, A., Ortiz-Navarrete, V., Ponce-de-Leon, A., et al. 2020. B cell subsets as severity-associated signatures in COVID19 patients. Front. Immunol. 11, 611004.

Suthar, M.S., Zimmerman, M., Kauffman, R., Mantus, G., Linderman, S., Vanderheiden, A., Nyhoff, L., Davis, C., Adekunle, S., Affer, M., et al. 2020. Rapid generation of neutralizing antibody responses in COVID-19 patients. Cell Rep. Med. 1, 100040.

Tang, F., Quan, Y., Xin, Z.T., Wrammert, J., Ma, M.J., Lv, H., Wang, T.B., Yang, H., Richardus, J.H., Liu, W., et al. 2011. Lack of peripheral memory B cell responses in recovered patients with severe acute respiratory syndrome: a six-year follow-up study. J. Immunol. 186, 7264-7268.

Trinité, B., Tarrés-Freixas, F., Rodon, J., Pradenas, E., Urrea, V., Marfil, S., Rodríguez de la Concepción, M.L., Ávila-Nieto, C., AguilarGurrieri, C., Barajas, A., et al. 2021. SARS-CoV-2 infection elicits a rapid neutralizing antibody response that correlates with disease severity. Sci. Rep. 11, 2608.

Trunfio, M., Calcagno, A., Bonora, S., and Di Perri, G. 2021. Lower- ing SARS-CoV-2 viral load might affect transmission but not disease severity in secondary cases. Lancet Infect. Dis. 21, 914-915.

Vigón, L., García-Pérez, J., Rodríguez-Mora, S., Torres, M., Mateos, E., Castillo de la Osa, M., Cervero, M., Malo De Molina, R., Navarro, C., Murciano-Antón, M.A., et al. 2021. Impaired antibody-dependent cellular cytotoxicity in a spanish cohort of patients with COVID-19 admitted to the ICU. Front. Immunol. 12, 742631.

Wang, P., Casner, R.G., Nair, M.S., Yu, J., Guo, Y., Wang, M., Chan, J.F.W., Cerutti, G., Iketani, S., Liu, L., et al. 2022. A monoclonal antibody that neutralizes SARS-CoV-2 variants, SARS-CoV, and other sarbecoviruses. Emerg. Microbes Infect. 11, 147-157.

Wang, E.Y., Mao, T., Klein, J., Dai, Y., Huck, J.D., Jaycox, J.R., Liu, F., Zhou, T., Israelow, B., Wong, P., et al. 2021. Diverse functional autoantibodies in patients with COVID-19. Nature 595, 283-288.

Weisblum, Y., Schmidt, F., Zhang, F., DaSilva, J., Poston, D., Lorenzi, J.C., Muecksch, F., Rutkowska, M., Hoffmann, H.H., Michailidis, E., et al. 2020. Escape from neutralizing antibodies by SARS-CoV-2 spike protein variants. eLife 9, e61312.

Wiseman, D.J., Thwaites, R.S., Drysdale, S.B., Janet, S., Donaldson, G.C., Wedzicha, J.A., Openshaw, P.J., and RESCEU Investigators. 2020. Immunological and inflammatory biomarkers of susceptibility and severity in adult respiratory syncytial virus infections. J. Infect. Dis. 222, S584-S591.

Wong, L.Y.R. and Perlman, S. 2022. Immune dysregulation and immunopathology induced by SARS-CoV-2 and related coronaviruses - are we our own worst enemy? Nat. Rev. Immunol. 22, 47-56.

Woodruff, M.C., Ramonell, R.P., Nguyen, D.C., Cashman, K.S., Saini, A.S., Haddad, N.S., Ley, A.M., Kyu, S., Howell, J.C., Ozturk, T., et al. 2020. Extrafollicular B cell responses correlate with neutralizing antibodies and morbidity in COVID-19. Nat. Immunol. 21, 1506-1516.

Wu, J., Liang, B., Chen, C., Wang, H., Fang, Y., Shen, S., Yang, X., Wang, B., Chen, L., Chen, Q., et al. 2021. SARS-CoV-2 infection induces sustained humoral immune responses in convalescent patients following symptomatic COVID-19. Nat. Commun. 12, 1813.

Xiang, T., Liang, B., Fang, Y., Lu, S., Li, S., Wang, H., Li, H., Yang, X., Shen, S., Zhu, B., et al. 2021. Declining levels of neutralizing antibodies against SARS-CoV-2 in convalescent COVID-19 patients one year post symptom onset. Front. Immunol. 12, 708523.

Xu, L., Ma, Z., Li, Y., Pang, Z., and Xiao, S. 2021. Antibody dependent enhancement: unavoidable problems in vaccine development. Adv. Immunol. 151, 99-133.

Yang, L., Li, J., Guo, S., Hou, C., Liao, C., Shi, L., Ma, X., Jiang, S., Zheng, B., Fang, Y., et al. 2021a. SARS-CoV-2 variants, RBD mutations, binding affinity, and antibody escape. Int. J. Mol. Sci. 22, 12114 .

Yang, Y., Wang, X., Du, R.H., Zhang, W., Si, H.R., Zhu, Y., Shen, X.R., Li, Q., Li, B., Men, D., et al. 2021b. Serological investigation of asymptomatic cases of SARS-CoV-2 infection reveals weak and declining antibody responses. Emerg. Microbes Infect. 10, 905-912.

Zhang, J., Lin, H., Ye, B., Zhao, M., Zhan, J., Dong, S., Guo, Y., Zhao, Y., Li, M., Liu, S., et al. 2021. One-year sustained cellular and humoral immunities of COVID-19 convalescents. Clin. Infect. Dis. ciab884.

Zhang, L., Zhang, F., Yu, W., He, T., Yu, J., Yi, C.E., Ba, L., Li, W., Farzan, M., Chen, Z., et al. 2006. Antibody responses against SARS coronavirus are correlated with disease outcome of infected individuals. J. Med. Virol. 78, 1-8.

Zhao, W., Zhong, Z., Xie, X., Yu, Q., and Liu, J. 2020. Relation between chest CT findings and clinical conditions of coronavirus disease (COVID-19) pneumonia: a multicenter study. Am. J. Roentgenol. 214, 1072-1077. 